\title{
LA CONJUNCIÓN TERRITORIO, PAISAJE, PATRIMONIO Y HERENCIA CULTURAL COMO PRODUCTO TURÍSTICO: EL CASO DEL VALLE DE RICOTE (REGIÓN DE MURCIA) SURESTE DE ESPAÑA
}

\author{
Miguel Ángel Sánchez-Sánchez \\ Universidad de Murcia \\ Departamento de Geografía \\ miguelangel.sanchez2@um.es \\ Francisco Belmonte Serrato \\ Universidad de Murcia \\ Departamento de Geografía \\ franbel@um.es \\ Gustavo Adolfo Ballesteros Pelegrín \\ Universidad de Murcia \\ Departamento de Geografía \\ gapb1@um.es
}

\section{Resumen}

En el Valle de Ricote, en el interior de la Región de Murcia, se mezclan montañas, huertas centenarias, y pequeños y medianos poblamientos, estructurados históricamente entorno al río Segura. La estructura territorial y paisajística de su zona central no ha variado en sus aspectos básicos en los últimos 500 años. La amalgama de naturaleza, cultura (romanos, árabes, judíos y cristianos), utilización del agua y el territorio, ha dado lugar a una singularidad paisajística de importante valor patrimonial, tal y como se recoge en las calificaciones otorgadas a sus elementos naturales y humanos. Dando lugar a un destacado interés turístico. El aislamiento tradicional ha sido una de sus características destacadas. Conocer los recursos del territorio con interés turístico, y la accesibilidad a los mismos, constituyen el objetivo de este estudio. Siendo localizados los elementos significativos en el territorio, y analizadas sus calificaciones. Además del análisis de la accesibilidad al Valle.

Palabras clave: Valle de Ricote, paisaje, patrimonio, huerta, turismo. 


\title{
THE TERRITORY CONJUNCTION, LANDSCAPE, HERITAGE AND CULTURAL HERITAGE AS A TOURIST PRODUCT: THE CASE OF THE RICOTE VALLEY (MURCIA REGION) SOUTHEAST OF SPAIN
}

\author{
Miguel Ángel Sánchez-Sánchez \\ Universidad de Murcia \\ Departamento de Geografía \\ miguelangel.sanchez2@um.es \\ Francisco Belmonte Serrato \\ Universidad de Murcia \\ Departamento de Geografía \\ franbel@um.es \\ Gustavo Adolfo Ballesteros Pelegrín \\ Universidad de Murcia \\ Departamento de Geografía \\ gapb1@um.es
}

\begin{abstract}
In the Ricote Valley, in the interior of the Region of Murcia, there are mountains, centenarian orchards, and small and medium-sized settlements, historically structured around the Segura River. The territorial and landscape structure of its central zone has not varied in its basic aspects in the last 500 years. The amalgamation of nature, culture (Romans, Arabs, Jews and Christians), use of water and territory, has given rise to a landscape singularity of important heritage value, as reflected in the qualifications given to its natural and human elements. Giving rise to an outstanding tourist interest. Traditional isolation has been one of its outstanding characteristics. Knowing the resources of the territory with tourist interest, and the accessibility to them, constitute the objective of this study. Being located the significant elements in the territory, and analyzed their qualifications. In addition to the analysis of the accessibility to the Valley.
\end{abstract}

Key words: Ricote Valley, landscape, heritage, orchard, tourism. 


\section{Introducción}

Para la Organización Mundial de Turismo [OMT] el turismo es un fenómeno cultural, social y con influencia económica, vinculado a la movilidad de las personas que se encuentran fuera de su lugar de residencia habitual por diversos motivos (OMT, 2017). Las actividades que realizan estas personas, durante el hecho turístico, por menos de un año y con fines diferentes (ocio, estudios, etc.) contribuyen a su definición (UCI, 2017). La importancia de esta actividad para países como España, que la han convertido en líder mundial, dando lugar a la creación del Plan del Turismo Español Horizonte 2020, entre cuyos objetivos se encuentra el aprovechar las fortalezas que han contribuido a ello. El turismo cultural se afianza como uno de los productos turísticos en España. Además otros como: los de salud y bienestar, deportivo, rural y de naturaleza se encuentran en pleno desarrollo (TURISMO 2020, 2007).

Ante tal situación el Valle de Ricote, ubicado aproximadamente en el centro geográfico de la Región de Murcia (figura 1), organizado en torno al río Segura en su tramo medio donde se observa una disposición de valles en cadena (figura 2), cuenta con elementos destacados capaces de conformar un conjunto de recursos turísticos con atractivo turístico suficiente para ofrecer una oferta turística de interés. Junto a los elementos del territorio destaca el paisaje como recurso turístico capaz de sintetizar la singularidad del territorio en cuestión. El interés por el paisaje no es una cuestión novedosa, es algo que ha interesado a las diversas culturas. En el siglo IV, el sentimiento por el paisaje ya era experimentado en China. El interés por el paisaje evoluciona de la mano de la popularización del viaje de placer, del gusto por conocer nuevos lugares. En este sentido y fruto de una posterior evolución de este fenómeno, inicialmente minoritario, podría decirse que el turismo en sus orígenes provoca el descubrimiento generalizado del paisaje (Canalís, 2014).

El interés que despiertan los paisajes del Valle de Ricote, viene recogido en las Directrices y Plan de Ordenación Territorial, que afectan al mismo. Orientar y promocionar un desarrollo territorial sostenible basado, entre otras cuestiones, en el mantenimiento y fomento de los paisajes rurales como activo de primer orden y el desarrollo turístico como un importante motor socioeconómico y fuente de identidad y valoración del territorio (BORM [Boletín Oficial de la Región de Murcia], 2014).

El Valle de Ricote como antiguo solar de los moriscos ricoteños se nos muestra todavía hoy como el resultado de una secular interacción entre factores naturales y humanos, aún es posible calificarlo como un valioso patrimonio natural, ambiental, cultural y social que merece ser bien gestionado y conservado (Calvo y López, 2014) (figura 2). 
La conjunción territorio, paisaje, patrimonio y herencia cultural como producto turístico: el caso del valle de Ricote (región de Murcia) sureste de España Gest. tur, $\mathrm{N}^{\circ} 29$, enero - junio 2018, pp 31-63.
Miguel Sánchez

Francisco Belmonte

Gustavo Ballesteros

Figura 1. Localización del Valle de Ricote

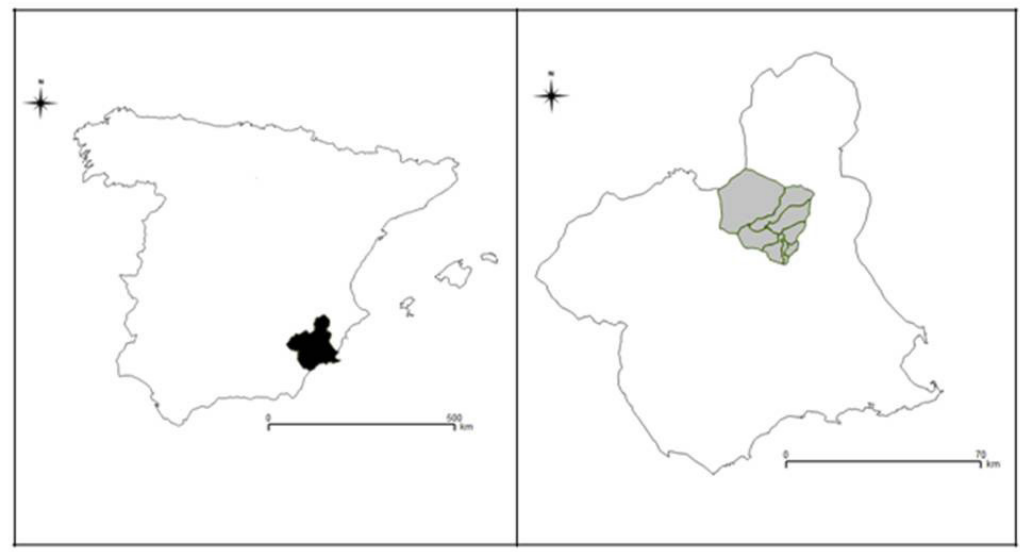

Figura 2. Vista aérea parcial del Valle de Ricote

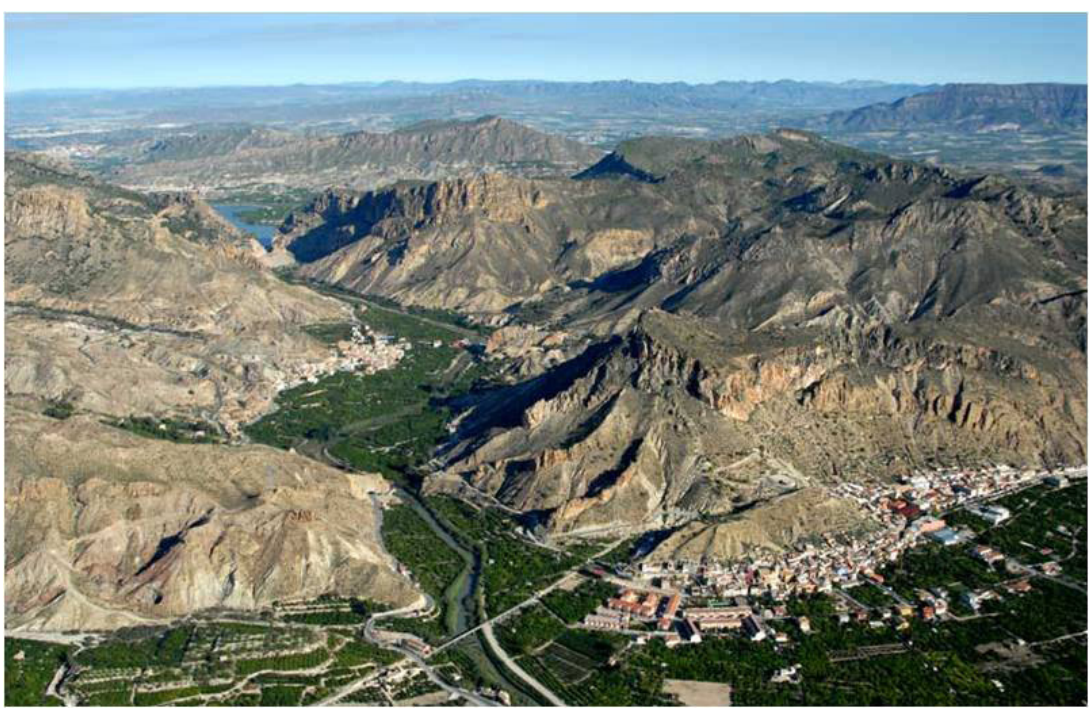

Fuente: Región de Murcia Digital, 2017. 
Se tiene como objetivo general identificar los elementos y paisajes del territorio con valor patrimonial que pueden definir el Valle de Ricote como de interés turístico, para conformar un producto turístico. Para ello los objetivos secundarios se basaron en el análisis y valoración de: los recursos turísticos, los atractivos turísticos, la planta turística, los servicios complementarios, los medios de transporte, y la infraestructura básica.

\section{Metodología}

Una vez definido el ámbito de trabajo, se analizan y valoran aquellos elementos que pueden constituir un recurso turístico. Recurriendo a los distintos catálogos y/o listados que categorizan los elementos destacados del territorio (catálogo de Bienes de Interés Cultural [BIC] de la Región de Murcia, Planes Generales Municipales de Ordenación [PGMO], etc.). Para cribar los mismos se sigue como criterios de selección su posible "valor patrimonial" inspirado en las definiciones de Patrimonio Cultural, Natural y Mixto de la UNESCO (1972). Considerando como "Patrimonio Cultural" los monumentos (obras arquitectónicas, elementos o estructuras de carácter arqueológico), conjuntos (grupos de construcciones, aisladas o reunidas...), lugares (obras del hombre y obras conjuntas del hombre y la naturaleza, así como las zonas, incluidos los lugares arqueológicos) con valor destacable o excepcional. "Patrimonio Natural" el conformado por monumentos naturales (formaciones físicas y biológicas o por grupos de estas formaciones), formaciones geológicas y fisiográficas y las zonas estrictamente delimitadas (que constituyan el hábitat de especies, animales y vegetales, amenazadas), y lugares naturales o las zonas naturales estrictamente delimitadas, todos ellos con interés especial, excepcional o significativo. "Patrimonio Mixto Cultural y Natural", bienes que responden parcial o totalmente a las definiciones de patrimonio cultural y natural expuestas. Además de la relevancia en los distintos catálogos y/o listados, en función su calificación en los mismos.

Los elementos presentes en el territorio contribuyen a definir paisajes singularizados en función de los elementos presentes. El paisaje, tal y como se recoge en el Convenio Europeo del Paisaje [CEP], es entendido como cualquier parte del territorio tal y como lo percibe la población, y cuyo carácter es consecuencia de la acción e interacción de factores naturales y/o humanos (Consejo de Europa, 2000). Esa interacción nos aproxima a la definición de paisajes culturales, ilustrando estos la evolución de la sociedad y sus asentamientos a lo largo del tiempo, condicionados por las limitaciones y/u oportunidades físicas que presenta su entorno natural y por las sucesivas fuerzas sociales, económicas y culturales (UNESCO, 1972, Pág. 48). Al paisaje se le puede atribuir la capacidad de síntesis de las relaciones entre grupos sociales y territorio, pudiendo ser considerado como un instrumento para el conocimiento del territorio en cuestión (Sánchez-Sánchez, 2017, Pág. 259). 
Dicho esto, se opta por utilizar como referencia de actuación la metodología utilizada por Silva (2014). Mediante la misma se realiza una aproximación espacial al territorio, con cambio de escalas más pequeñas y globales, hacia escalas más grandes y de detalle. Las etapas de aproximación definen diversos marcos, en los cuales perfectamente encaja la concepción de paisaje tal y como es tratada en este trabajo a la luz del CEP2000. La primera etapa permite la contextualización territorial del área de estudio, donde el territorio es visto como soporte físico-natural, espacio geográfico-relacional (nodos - poblaciones-, redes -vías de comunicación-) y contexto socioeconómico-cultural. En la segunda se hace referencia a las periferias urbanas, destacando las interfaces urbano-rurales y los paisajes híbridos de campo-ciudad. Estos bordes muestran áreas de interés paisajístico por la existencia de huertas tradicionales, etc. y las vías de acceso a las poblaciones de las que en algunos casos se obtienen imágenes significativas o de conjunto. Ya en un ámbito más urbano, son estudiados los paisajes interiores de estos. Este interior urbano se organiza en las diferentes piezas (o barrios) que articulan su trama urbana y, dentro de cada unidad, en los rasgos básicos de sus redes de espacios libres públicos. Finalmente hay que decir que esta forma de operar permite una aproximación más integral al territorio, paisajes y elementos.

Al tiempo que se van ejecutando cada una de las anteriores fases, de modo simultáneo, se van analizando y valorando los elementos encontrados que pueden constituir un recurso turístico y que a su vez tienen atractivo turístico. Una vez definidos estos se analiza y valora la planta turística, los servicios complementarios, medios de transporte e infraestructuras básicas que nos pueden llevar a sentar las bases para generar un producto turístico (cuadro 1).

Cuadro 1. Componentes del producto turístico.

\begin{tabular}{|l|l|}
\hline \multirow{4}{*}{ PRODUCTO TURÍSTICO } & Recurso turístico \\
\cline { 2 - 2 } & Atractivo turístico \\
\cline { 2 - 2 } & Planta turística \\
\cline { 2 - 2 } & Servicios complementarios \\
\cline { 2 - 2 } & Medios de transporte \\
\cline { 2 - 2 } & Infraestructura básica \\
\hline
\end{tabular}

Fuente: UCI (2017) 


\section{Resultados y discusión}

\subsection{Delimitación del área de estudio}

La delimitación geográfica de Valle de Ricote resulta algo confusa. En 1984 Fuentes Zorita y Calvo consideran que Ojós, Ricote, Villanueva del Río Segura y Ulea forman la comarca "Valle de Ricote". En todas las comarcalizaciones realizadas hasta la fecha, Ojos, Ricote, Villanueva del Río Segura y Ulea siempre aparecen unidas, y en tres de éstas se les unirán Abarán, Archena, Blanca y Cieza.

En relación a esta cuestión, y a efectos del presente trabajo, se tiene en cuenta la propuesta de Valle de Ricote en la que esta área geográfica bien podría ser dividida en dos zonas: a partir de los márgenes del río, la circunscrita a su entorno más inmediato, y delimitada por los relieves montañosos más próximos; y otra externa, más allá de estos relieves. Igualmente, el cierre del valle aguas arriba bien podría situarse en Medina Siyâsa (Cieza), y aguas abajo en el Balneario de Archena (Sánchez-Sánchez et al., 2014). En una primera aproximación a esa zona que bien podría ser denominada central o interior hay tres aspectos que destacan sobremanera: los relieves montañosos que lo circundan, las huertas junto con el río y los asentamientos humanos. La zona externa o exterior va desde el perímetro de la central hasta los límites más externos de los municipios de Abarán, Blanca, Ojós, Ricote, Ulea y Villanueva del río Segura (figura 3).

Figura 3. Delimitación del área de estudio.

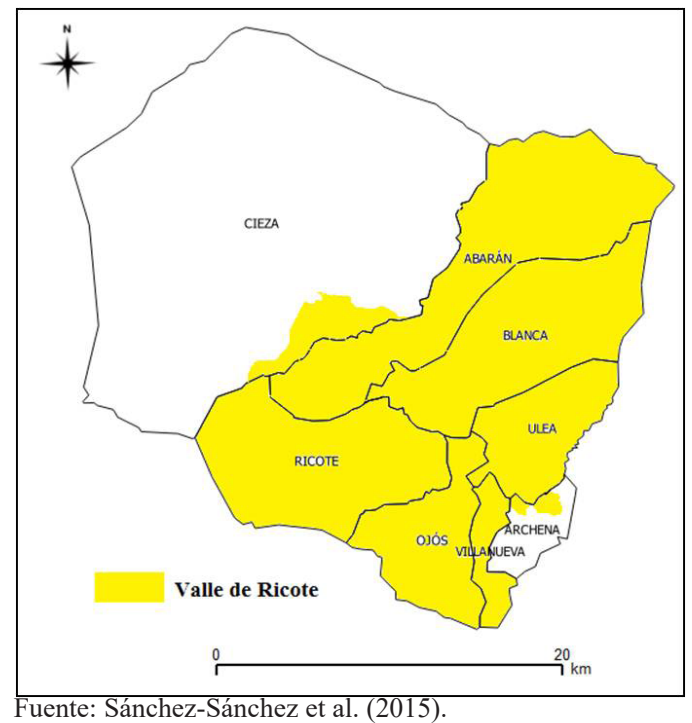




\subsection{Aproximación geográfica al Valle de Ricote}

\subsubsection{Contexto territorial}

El Valle de Ricote se sitúa en el dominio Subbético de las Cordilleras Béticas levantadas por la orogenia alpina, presenta una compleja geología debido a la variedad de rocas, cabalgamientos y fallas que ofrece. Estructuras de amplios y suaves pliegues anticlinales y cabalgamientos se hallan en las diversas sierras que circundan el valle; entre ellas se hallan depresiones topográficas rellenas con formaciones post-orogénicas de la segunda mitad del Terciario y del Cuaternario, son materiales blandos muy sensibles a los procesos de erosión, por lo que las cárcavas son formas de paisaje dominantes.

Las fuerzas orogénicas, la tectónica y los mecanismos de modelado han originado, además de los relieves mayores de las sierras que constituyen el armazón del valle (figura 2), las siguientes formaciones: (a) estrechamientos (Bolvax, El Menjún, Blanca y Baños de Archena) en angostos desfiladeros (El Solvente y el Salto de la Novia)(figura 4A y 4B); (b) una rica y variada topografía de cabezos, cerros y lomas a ambos lados del valle; de Cieza a Archena y por la margen derecha destacan: los Cerros de la Atalaya y del Castillo, Cabezo del Molinera, etc.. Por la margen izquierda: Cerro del Morrón, Pila de la Reina Mora, etc.

Entre estos relieves, las aguas de las escorrentías generadas por las precipitaciones han originado redes de drenaje: ramblas y barrancos que vierten episódicos caudales al río Segura. Las terrazas fluviales son geoformas-depósitos que se originan cuando el río sedimenta su carga de mteriales en el valle y después se encaja en ellos originando un depósito o escalón colgado (Calvo y López, 2014) (figura 4A).

Figura 4. A) Río Segura (Blanca). B) Salto de la Novia (Ulea/Ojós).

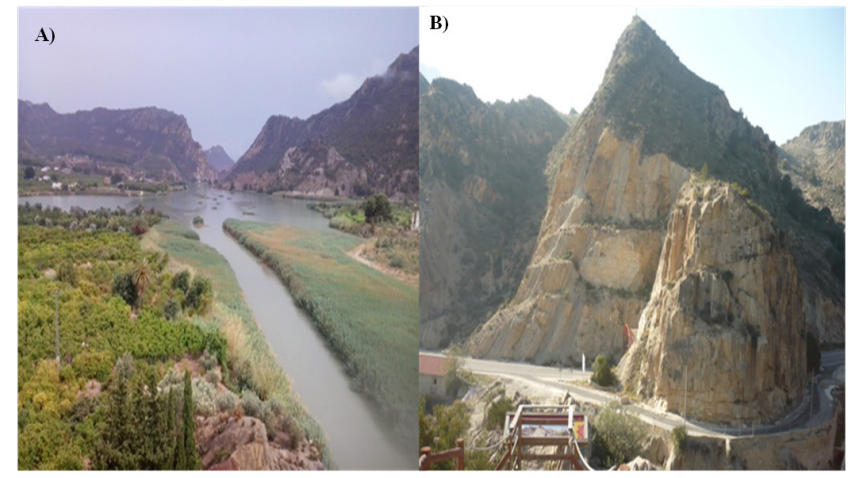

Fuente: Sánchez-Sánchez, M.A. (2017) 
La vegetación de ribera es uno de los aspectos vegetales destacables junto a los pinares en las zonas de sierra, abundan los vegetales xéricos. El clima es templado, pero algo diverso, consecuencia de la diferencia de altitud (Balneario de Archena -110 m-, Almeces $-1.124 \mathrm{~m}-$, en la zona central; y en la externa la mayor altitud, 1.264 en la Sierra de la Pila) y orientación, con una precipitación media de $300 \mathrm{~mm}$ anuales y temperatura media anual de $18^{\circ} \mathrm{C}$, que desciende con la altitud y continentalidad.

Las poblaciones que conforman el Valle de Ricote son diversas, desde las cabeceras municipales (Abarán, Blanca, Ojós, Ricote, Ulea y Villanueva) hasta pequeños poblados como Bolvax (Cieza), todos ellos situados en el interior del valle. Otros quedan fuera de la zona central, con tal número de habitantes que en algunos casos se acercan al volumen presente en las cabeceras e incluso lo superan, tal es el caso de la: Hoya del Campo (Abarán) y Estación de Blanca/Abarán.

Existe una considerable trama de caminos y carreteras, pero las de mayor importancia son: la autovía A-30 (Albacete-Cartagena) que discurre paralela al Valle, A-33 (puerto de La Losilla-Yecla) en dirección nortenoreste y las distintas comarcales que discurren por el interior del Valle.

Los usos del suelo son mayoritariamente agrícolas y forestales. Las costumbres y herencias más comunes entre las poblaciones del valle son el aprovechamiento tradicional de la actividad agrícola mediante el uso del agua y el suelo, creando una red hidráulica y un aprovechamiento agrícola del territorio intensivo.

Aunque sólo puede considerarse Abarán (13.179 habitantes) como pequeña ciudad (cuadro 2) [Blanca (6.521); Villanueva del Río Segura (2.524); Ricote (1.369); Ulea (906); y Ojós (504) (CREM [Centro Regional de Estadística de Murcia], 2015)], la metodología propuesta por Silva (2014) parece poder aplicarse a núcleos poblaciones aún sin consideración de medianas o pequeñas ciudades.

El Valle de Ricote, con todos sus componentes materiales e inmateriales, constituye un hecho geográfico asociado a un territorio, por lo que se justifica su contextualización territorial como una aproximación al mismo. Con un cambio de escala se aprecia la interface entre los asentamientos urbanos y su entorno (rural, industrial, etc.), independientemente del tamaño poblacional de los mismos (poblado, pequeña, mediana y gran ciudad). Todo núcleo urbano posee paisajes interiores, definidos por su trama urbana y espacios libres. Siendo apropiado tomar como referencia la metodología utilizada por Silva (2014). 
Cuadro 2. Diferencias entre los núcleos de población urbanos (ciudad) y rurales

\begin{tabular}{|c|c|c|}
\hline CRITERIO & CIUDAD & NÚCLEO RURAL \\
\hline CUANTITAVO & $\geq 10.000$ habitantes & 10.000 habitantes $<$ \\
\hline \multicolumn{3}{|l|}{ CUALITATIVO } \\
\hline ASPECTO FÍSICO & $\begin{array}{l}\text { - Edificacion y poblacion de alta densidad. } \\
\text { - Predomino de viviendas colectivas y en } \\
\text { altura. }\end{array}$ & $\begin{array}{l}\text { - Baja densidad de población y de } \\
\text { edificación. } \\
\text { - Predominio de viviendas individuales } \\
\text { y de baja altura. }\end{array}$ \\
\hline $\begin{array}{l}\text { ACTIVIDADES } \\
\text { ECONÓMICAS }\end{array}$ & $\begin{array}{l}\text { - Predominio de población activa en sector } \\
\text { secundario y terciario. }\end{array}$ & $\begin{array}{l}\text { - Predominio de la población ocupada } \\
\text { en las actividades del sector primario }\end{array}$ \\
\hline $\begin{array}{l}\text { RASGOS } \\
\text { SOCIALES }\end{array}$ & $\begin{array}{l}\text { - Diversidad social. } \\
\text { - Relaciones más impersonales y anónimas }\end{array}$ & $\begin{array}{l}\text { - Menor diversidad social } \\
\text { - Estructuras familiares y relaciones } \\
\text { sociales mas estrechas. }\end{array}$ \\
\hline $\begin{array}{l}\text { INFLUENCIA } \\
\text { SOBRE EL } \\
\text { ENTORNO }\end{array}$ & $\begin{array}{l}\text { - Influyen o dirigen su entorno, por las } \\
\text { funciones político-administrativas, } \\
\text { económicas y culturales que desempeñan. }\end{array}$ & $\begin{array}{l}\text { - Los núcleos rurales dependen de las } \\
\text { ciudades para satisfacer ciertas necesidades } \\
\text { politico-administrativas, económicas y } \\
\text { culturales. }\end{array}$ \\
\hline
\end{tabular}

Fuente: Vicedo Pellin, M. (2011).

Los elementos naturales presentes en el Valle no pueden ser calificados como tal puesto, que, de un modo u otro, se han visto afectados por la acción humana, ésta en ocasiones ha favorecido al medio (repoblaciones forestales) dejando sobre el mismo una huella de connotación cultural. No obstante, los elementos naturales, los espacios naturales o paisajes naturales, pueden ser denominados como tal por el predominio en ellos de procesos naturales, pudiendo configurarse como un recurso turístico (UCI [Universidad para la Cooperación Internacional], 2017).

Los sistemas forestales o montes desempeñan múltiples funciones; una de ellas es la función socioeconómica, al generar bienes y servicios económicos y sociales. Pero no sólo proporcionan recursos materiales, sino otros servicios o bienes inmateriales necesarios para la sociedad que los demanda y que contempla los sistemas forestales como elementos indispensables del paisaje, escenario de actividades recreativas en tiempo de ocio (Estrategia Forestal Región de Murcia, 2003) (figura 5A, 6A). 
Figura 5. A) Umbría Sierra de Ricote. B) Solana Sierra de Ricote.

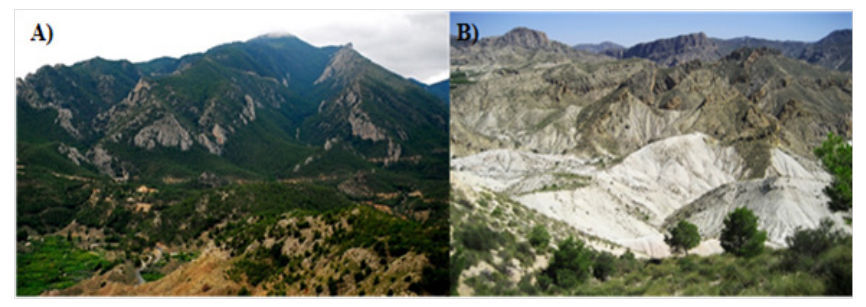

Fuente: A) www.montanasdelsur.es. B) Murcianatural (2015).

El bosque, como símil de monte, siempre ha constituido un recurso para la sociedad, no sólo para producir bienes materiales, sino también como un espacio para satisfacer a las personas, tanto cultural como espiritualmente, siendo un recurso turístico cada día más valorado. El atractivo turístico recreativo de los bosques no es generalizado, sino que normalmente la población se siente atraída por los árboles monumentales y por los bosques peculiares o con encanto. La mirada turística rara vez se orienta al conjunto de la superficie forestal, los visitantes se sienten atraídos por los nodos, los itinerarios, los escenarios, los elementos invisibles, los espacios o las redes de espacios forestales. Los nodos son la materia prima del turismo. Muchos turistas identifican un espacio a partir de estos nodos, aquello que debe ser visto. Los visitantes también pueden consumir escenarios, y buscan especialmente un decorado en el que desarrollar actividades ordinarias (figura 5A, 5B, 6A, 6B).

En la mayoría de casos, el consumo de los bosques se centra en el conjunto del espacio, los turistas se sienten atraídos por unos determinados valores que asignan a las zonas forestales, y que condicionan el comportamiento de los visitantes en el territorio. Sea como fuere, algunas formas de consumo de los bosques serán motivados por la totalidad del espacio, aunque la evidencia empírica demuestra que el recorrido efectivo se reduce a un área muy concreta. Algunas formas de consumo ponen el acento en la sucesión de espacios forestales, que no están necesariamente relacionados entre sí. Esta práctica es muy común en el turismo urbano o cultural y está en la génesis del propio turismo, los bosques son el hilo conductor de toda la oferta turística de la región (Donaire y Gordi, 2003). 
Figura 6. A) Bosque de Pino Carrasco. B) Palmeras datileras.

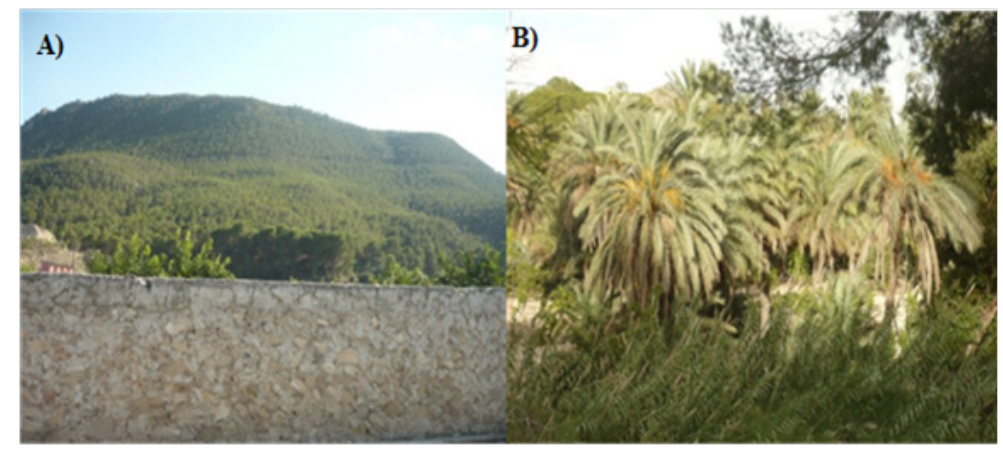

Fuente: Sánchez-Sánchez, M.A. (2017)

En el caso del Valle los espacios naturales destacados son: el Parque Regional Sierra de la Pila, en la periferia del área de estudio; y los espacios que forman parte de la Red Natura 2000: Sierra de La Pila; y Sierra de Ricote y La Navela (Zonas de Especial Protección para las Aves [ZEPA]) en aplicación de la Directiva Comunitaria de Aves. Además, estos, junto a los Yesos de Ulea, obstentan la calificación de Lugares de Importancia Comunitaria [LIC] por albergar hábitats de interés comunitario en aplicación de la Directiva Comunitaria sobre Hábitats (figura 7). Debe hacerse notar que sobre el territorio de la Sierra de la Pila confluyen tres calificaciones ambientales.

Figura 7. Mapa de distribución de espacios naturales protegidos (Red Natura 2000) en el área de estudio.

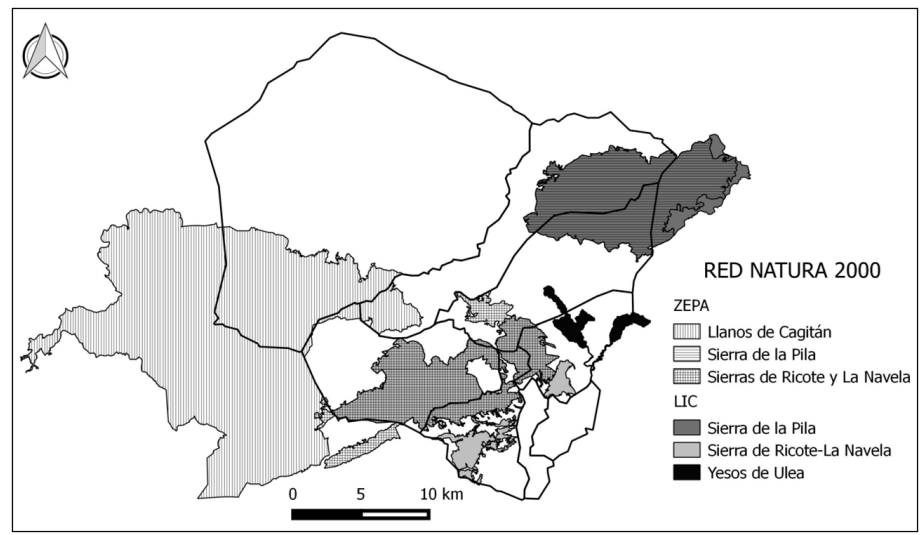

Fuente: Sánchez-Sánchez, M.A. (2017). 
Uno de los elementos que vincula lo natural con lo humano, es el río Segura (figura 4A), transcendental para la cultura y el paisaje del Valle. Junto al mismo se han desarrollado huertas, de carácter centenario, dando lugar a lo que podríamos denominar paisajes rurales, siendo estos, predominantes en el Valle. En su zona interior se da una agricultura tradicional, mientras que en la externa se practica de modo generalizado una más moderna y productivista, con menor interés cultural, patrimonial y turístico.

Figura 8. A) Huerta tradicional junto al río Segura. B) Huerta tradicional de Ricote.

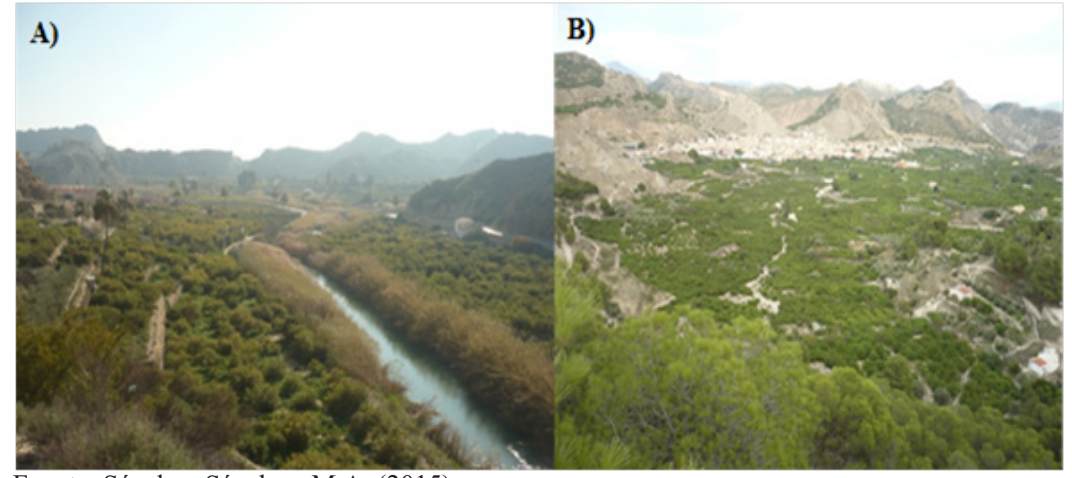

Fuente: Sánchez-Sánchez, M.A. (2015).

Las huertas tradicionales (figura 8A, 8B) del Valle de Ricote, junto con la red de regadíos, las técnicas agronómicas utilizadas, los bienes naturales y culturales, materiales e inmateriales, generados o aprovechados por la actividad agraria a lo largo de la historia del Valle, constituyen un patrimonio agrario de interés (Castillo y Martínez, 2014). Silva (2008) entiende como patrimonio agrario todo aquel legado relacionado con la herencia histórica de la explotación agropecuaria, entendida ésta en un sentido amplio (áreas de cultivo, dehesas, pastizales, plantaciones forestales), bien sea de carácter material (paisajes, edificios relacionados con la producción y la transformación de los productos de la agricultura, infraestructuras y equipamientos agrarios, determinados tipos de hábitat rural...) o etnográfico (oficios, artesanías, folklore...).

En documentos de 1533 ya se menciona la huerta de Ulea como la más rica del Valle de Ricote (Palazón, 2011), lo que demuestra la antigüedad de las huertas del Valle y, por tanto, su valor patrimonial. 
Las Directrices y Plan de Ordenación Territorial [DPOT] que afectan al área de estudio, en su normativa consideran a estos territorios agrarios, del Valle, como áreas singulares con especial interés calificándolas como Paraísos Rurales (art. 47), al tiempo que los ve como suelos a proteger por el interés paisajístico y agro-fluvial (BORM, 2014). El valor patrimonial de los regadíos históricos es consecuencia de una combinación de factores que dan lugar a paisajes valiosos y valorados. Entre estos factores cabe señalar las estructuras espaciales dibujadas por las infraestructuras hidráulicas (sintetizadas en la red de acequias) y las de comunicación (red de caminos), entre otros (Hermosilla e Iranzo, 2014) (figura 9A, 9B). El territorio del Valle de Ricote puede presumir de poseer gran cantidad de obras hidráulicas históricas, algunas como el Azud del Menjú, cuya fecha de construcción es totalmente desconocida (Pelegrín, 2012) (figura 9A, 9B, 12A).

Figura 9. A) Noria Grande de Abarán; B) Noria de la Hoya D. García (Abarán).

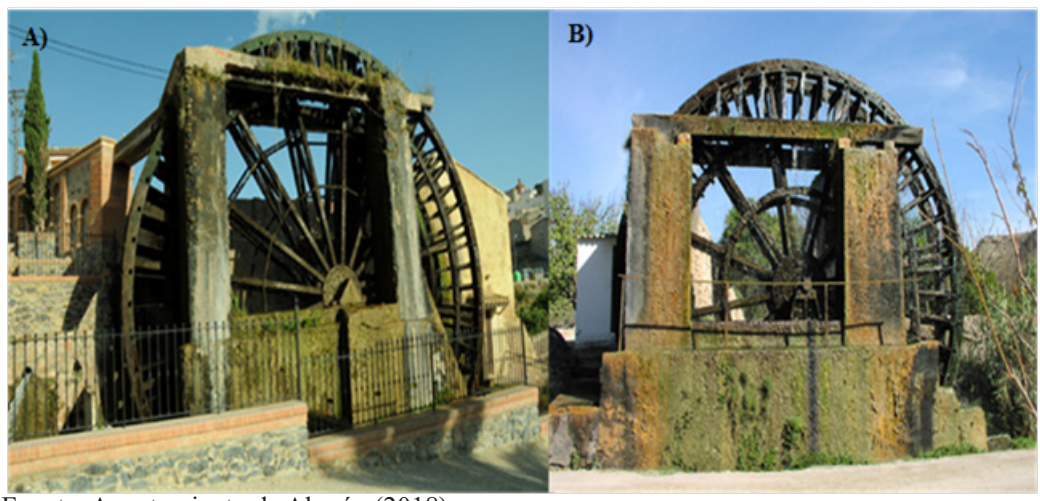

Fuente: Ayuntamiento de Abarán (2018).

\subsubsection{Las periferias urbanas o interfaces urbano-rurales}

Se dan paisajes agrícolas y forestales en el borde de todos los núcleos poblacionales. Los paisajes agrícolas están constituidos por huertas tradicionales donde se incardinan elementos propios de la red hidráulica (norias, acequias, etc.). En las poblaciones pequeñas, el paso de lo urbano a la huerta es directo, pareciendo no existir estas interfaces urbano-rural.

Las vías de acceso al Valle permiten una visión panorámica. Aquellas que facilitan el acceso a los distintos núcleos, llegan a mostrar un escenario singular, constituyéndose en señas de identidad de las distintas poblaciones existente (figura 10). 
Figura 10. Accesos A) Ulea. B) Villanueva del Río Segura. C) Ulea. D) Blanca.

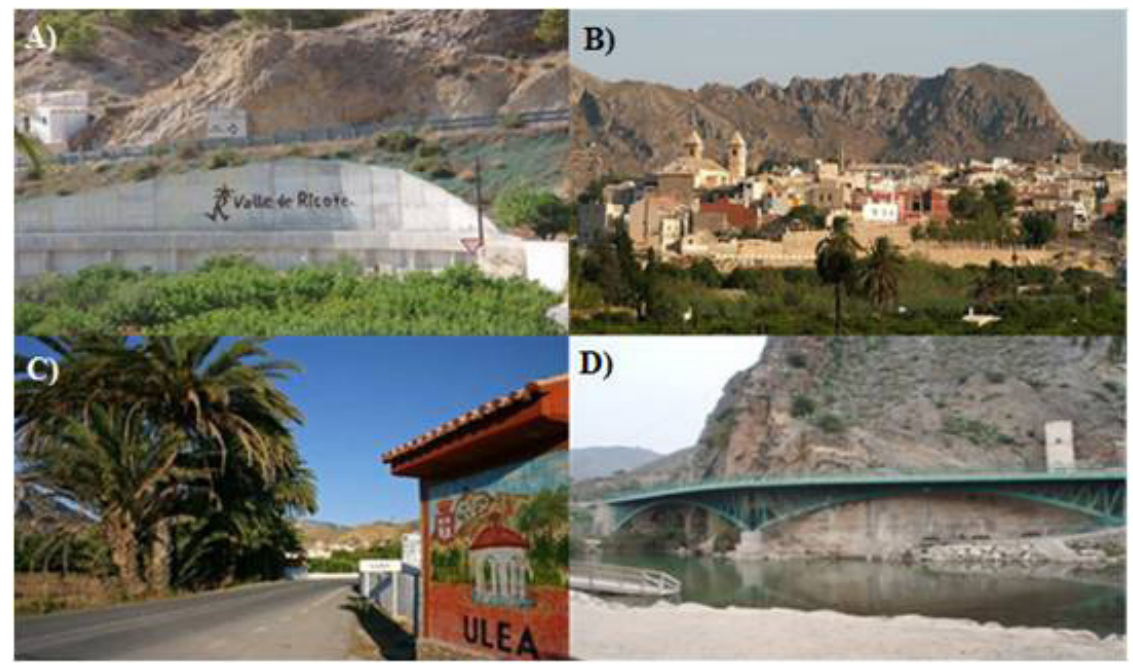

Fuente: B) www.regiondemurcia.com C) www. ruralmur.com D) Periódico La Verdad (2017).

\subsubsection{Los paisajes interiores urbanos.}

Los paisajes urbanos interiores de las poblaciones de Abarán, Blanca, Ojós y Ulea están supeditados a su trama urbana, condicionada por aspectos naturales como son la presencia del río Segura y los relieves próximos (figura 11A, 11B). Aunque Ricote no se encuentra en esta situación, sigue un modelo parecido. Este puede ser definido por la distribución del caserío en torno al relieve montañoso, siguiendo las curvas de nivel, dando lugar en algunos de los casos a la tipología de pueblo calle (figura 11B). En algunos de los casos, la distribución parte desde un polo originario próximo a una fortaleza, como Blanca. 
Figura 11. Imagen Satelital de: A) Abarán y B) Ojós

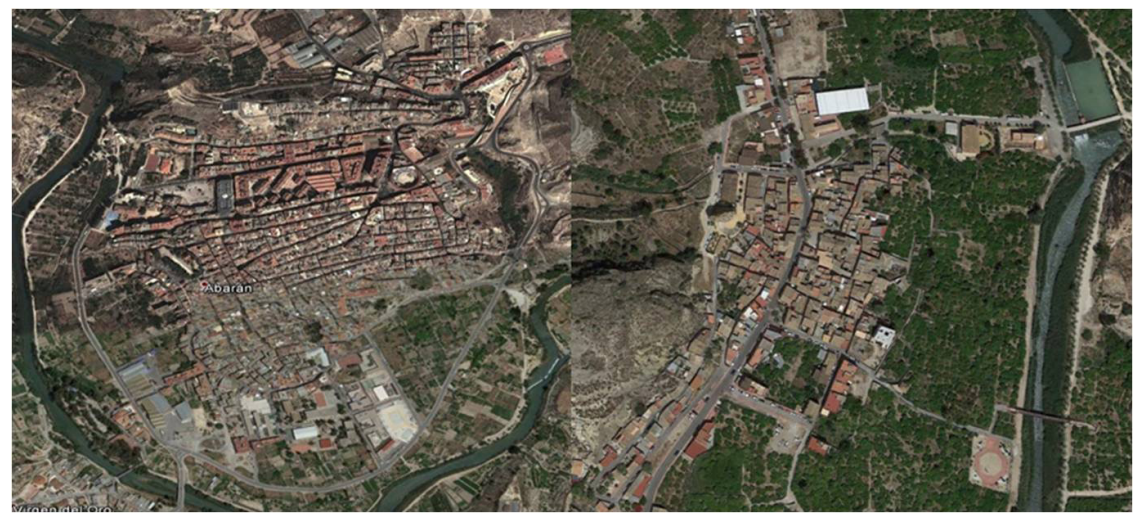

Fuente: Google earth (2017).

Las plazas actúan como zona de actividad social en las distintas poblaciones. Algunas albergan ayuntamiento e iglesia (Villanueva y Ulea), otros elementos destacados (El Henchidor-Ulea), y las hay en las que se localiza una plaza de toros(Abarán). Las condiciones naturales, junto a las históricas, han dado lugar a calles peculiares (figura 12A, 12B, 12C).

Figura 12. A) Calle Ulea. B) Calle Ojós. C) Calle de Ulea.

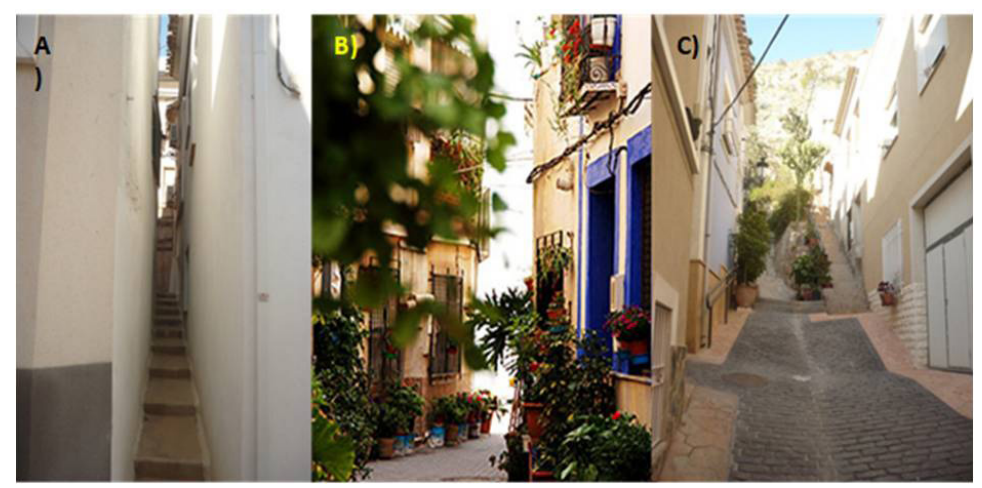

Fuente: A y C (Sánche-Sánchez, M.A., 20...) Ulea (propia), calle Ojós (www.valledericote.com) (2017). 
En el interior de las poblaciones del Valle cuenta con gran cantidad de elementos arquitectónicos de significativo interés y valor, buena parte de ellos están afectados por alguna figura de protección de las distintas administraciones (figura 13).

Figura 13. A) Teatro Cervantes de Abarán; B) Ayuntamiento de Blanca.

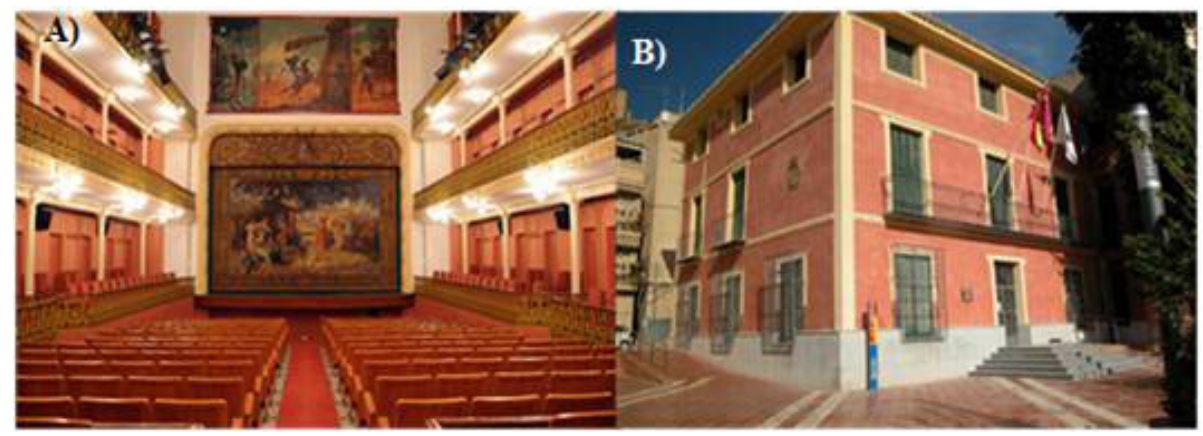

Fuente: A) Ayuntamiento de Abarán; B) www.murciadigital (2017).

En el casco urbano de Ulea destaca la Casa del Cura (Figura 14A) edificación peculiar que singulariza la plaza en la que se sitúa, aportando un aspecto pintoresco por su color y tipología constructiva. La Iglesia de Ulea fue construida en 1505 preservando vestigios originales, como es el "artesonado de estilo Mudejar", hecho que no ocurre en las otras iglesias del Valle de fechas constructivas próximas (Carrillo, 2014) (Figura 14B).

Figura 14. A) Casa del Cura (Ulea); B) Iglesia de S. Bartolomé (Ulea).
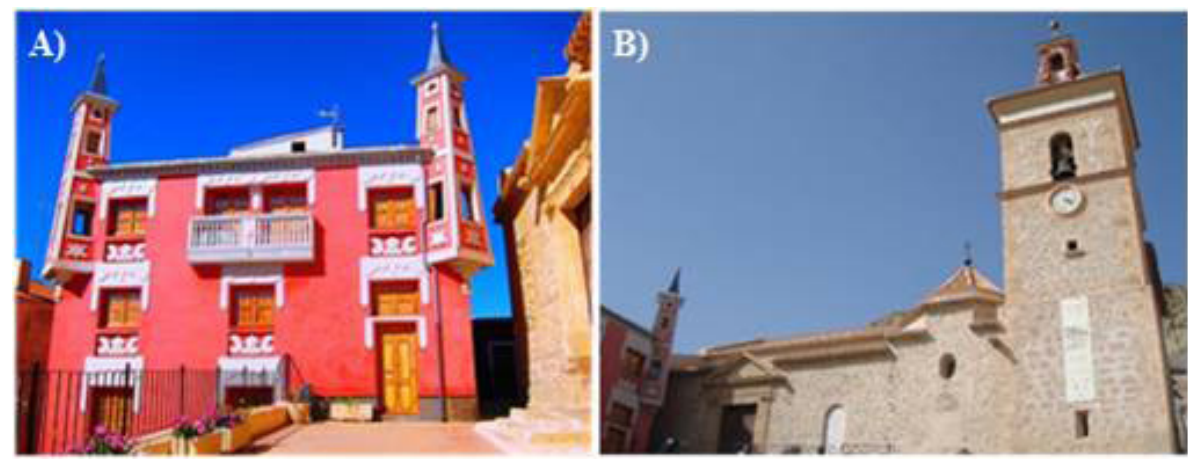

Fuente: A) Descubriendomurcia; B) www.regmurcia.com (2017). 
En Ricote durante el siglo XVI se construye el edificio de la Encomienda del Valle de Ricote (figura 15A), que será también la casa del Comendador, ostentando lo que podríamos venir a llamar la capitalidad del Valle de Ricote durante esa época histórica. El palacio de la familia Llamas, grandes señores del Valle de Ricote durante los siglos XVII y XVIII, construido en el siglo XVIII, de estilo barroco, ha sido sede del Ayuntamiento y actualmente lo es del Centro Cultural (biblioteca, archivo, museo, etc.) (Ayto. Ricote, 2018) (figura 15B).

Figura 15. A) Sede de la Encomienda del Valle de Ricote; B) Palacio de Los Llamas

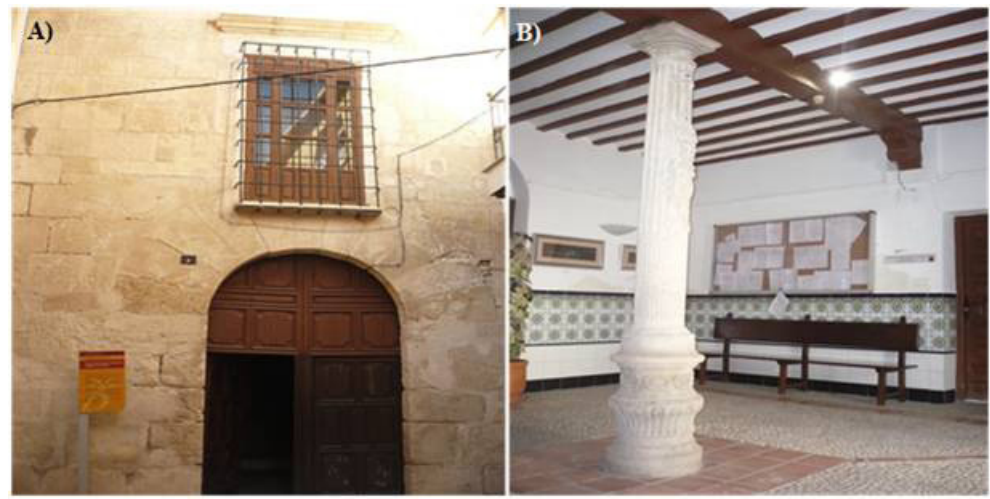

Fuente: Sánchez-Sánchez, M.A. (2015).

A los elementos descritos cabe añadir otros como el castillo de Blanca, icono del paisaje de destacada visualización, construido en el siglo XII, atribuyéndosele la construcción al Rey Lobo (figura 16A) y el poblado musulmán del siglo XI conocido como Medina Siyâsa, localizado en Cieza. Es el yacimiento arqueológico más importante en la decoración islámica de Europa (Región de Murcia Digital, 2015), llego a ser en su época la ciudad más grande del Valle y su entorno próximo, llegando albergar 4.000 personas (Gómez, 2016) (figura 16B).
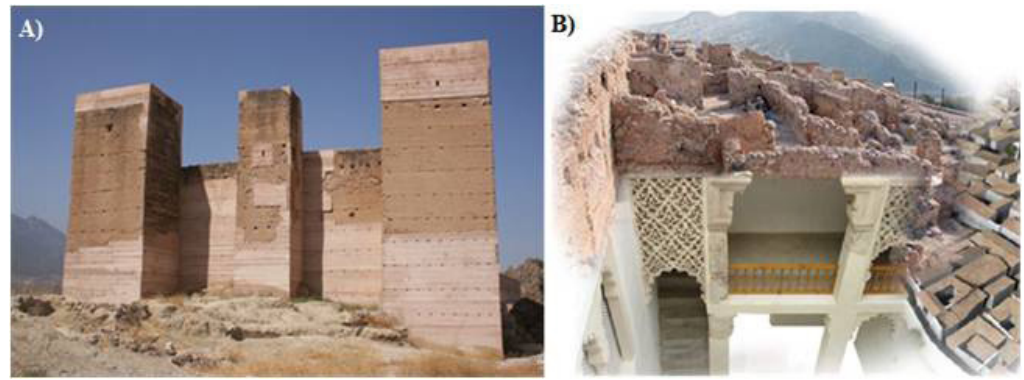

Fuente: A) Ayuntamiento de Blanca; B) Región de Murcia Digital (2017). 


\subsection{Espacios inmateriales}

Existen en el Valle algunos hechos destacables que conforman hitos acecidos en tiempos pretéritos, pero que se han perpetuado con el paso de los años, constituyendo parte de la cultura e identidad del mismo. Estos tienen una base física al estar localizados en lugares determinados del territorio y asociados a elementos materiales, aunque con una componente muy destacada de carácter inmaterial que los fundamenta. Este subapartado son tratados, algunos de los más destacados por su valor patrimonial y cultural, ya que contribuyen a enriquecer el territorio y el paisaje.

\subsubsection{Lignum Crucis (Ulea)}

No se sabe a ciencia cierta cuando llega el Lignum Crucis, una astilla de la cruz de Cristo, a Ulea. Parece que los caballeros de la Orden de Santiago, que administraban la población, en unos de sus viajes a Tierra Santa lo trajeron para recompensar al pueblo por el apoyo a la Orden (Región de Murcia Digital, 2015). Ulea, por su veneración a la Santa Cruz, se incluye en el denominado Camino del Lignum Crucis, que une Granja de Rocamora (Alicante), Abanilla y Caravaca de la Cruz (Murcia), también poseedores de Lignum crucis, conformando uno de los Caminos de la Cruz. Existe en la localidad una construcción "El Henchidor", donde se realiza el baño de la cruz al igual que en Caravaca

\subsubsection{Encierros (Blanca)}

Declarados de interés turístico regional, parece que se realizaron por primera vez en 1856. Destacan entre los realizados en otras localidades del sureste español (Moratalla y Calasparra -Murcia-; Hellín -Albacete-). La ciudad de Blanca se transforma físicamente esos días, cambia su paisaje urbano (figura 17).

Figura 17. Monumento a los Encierros de Blanca.

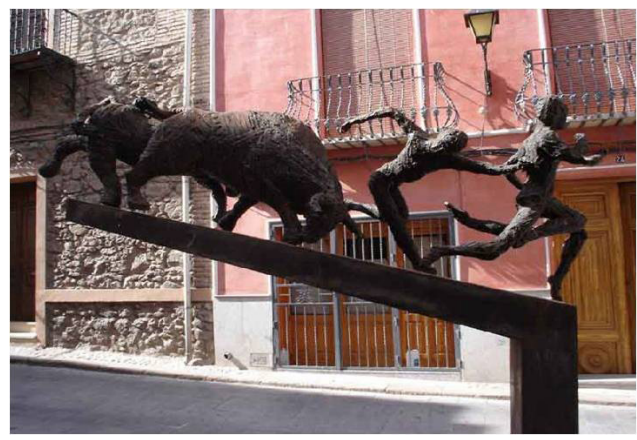

Fuente: regiondemurcia (2017). 


\subsubsection{Moros y Cristianos (Archena)}

Estas consisten en la representación de una Embajada Teatral, la entrega de la Carta Puebla por parte de la Orden de San Juan de Jerusalém, dueña de estas tierras desde la Reconquista Cristiana, a los mudéjares que aún quedaban residiendo en el municipio de Archena, en 1462. Esta Carta, pretendía fomentar la repoblación, una vez pacificada la zona, por estar muy próxima la conquista de Granada (Ayto. Archena, 2018).

\subsubsection{Museos del Valle de Ricote}

El Valle de Ricote cuenta con varios museos: Museo de los Belenes del Mundo (Ojós), Museo de la Luz y el Agua (Blanca), y Museo de Pintura Pedro Cano (Blanca).

\subsection{Paisajes del agua}

El agua es un elemento de primordial importancia para el Valle de Ricote por el aprovechamiento ancestral de la misma, tanto para la explotación agrícola, como para el uso doméstico y producción de energía eléctrica. Dejando una marca, una huella, en forma de modos de explotación, artilugios hidráulicos, etc., sobre el territorio, producto de la relación de la sociedad con la naturaleza y paisajes preexistentes, todo ello da al paisaje la consideración de patrimonial (Hermosilla e Iranzo, 2014). El agua es ese factor natural, de primer orden, en torno al cual han girado las relaciones sociales históricas del Valle, e incluso actuales, llegando a poder ser vistos los paisajes actuales como "paisajes del agua" (Mata y Fernández, 2010) (figura 18).

Figura 18. Embalse de Blanca

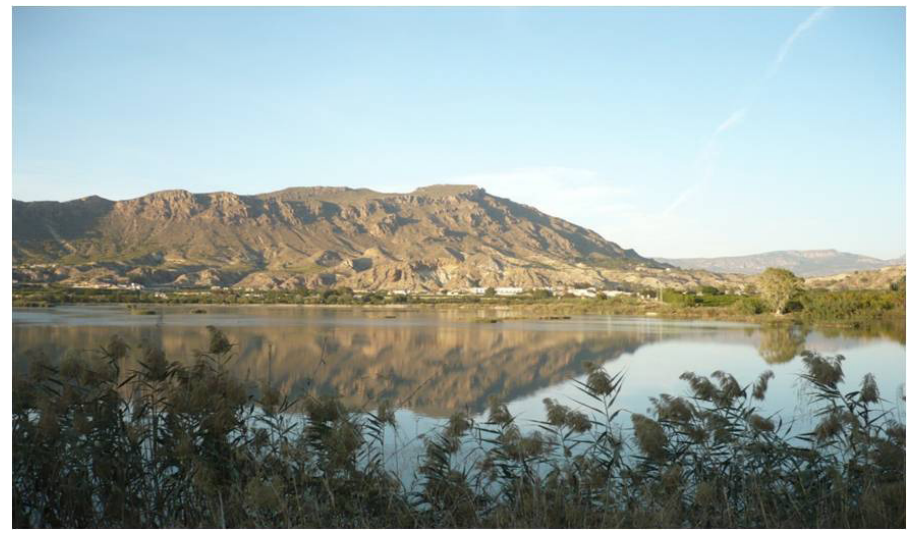

Fuente: Sánchez-Sánchez, M.A. (2015). 
Se aprecia un paisaje (huertas, río, elementos hidráulicos, etc.) que nos hacen tener la sensación que el motor de todo aquello en buena medida es el "agua". Haciendo de los paisajes del Valle un todo territorial morfológico, funcional y percibido, en el que el agua desempeña un papel protagonista en su génesis y configuración actual, en su funcionamiento y dinámica, y en la percepción social y cultural del territorio (Mata y Fernández, 2010). El origen agrícola de este aprovechamiento lo constituyen los azudes (figuras 19A, 19B), junto a las acequias y norias que conforman el entramado hidráulico del regadío tradicional. Tal es la antigüedad de algunos de estos elementos que en el caso del azud del Menjú se desconoce su fecha de construcción (Pelegrín, 2012).

Gracias al agua el territorio es transformado, apareciendo la actividad agrícola intensiva de regadío, que con el paso de los años será imagen de la huella dejada por las distintas sociedades, reflejo de las diversas culturas que habitaron el Valle, adquiriendo estas un valor cultural y por ende patrimonial, tal circunstancia es reconocida en diversos documentos normativos regionales. De este modo queda recogido su valor, tal y como propugna Silva (2008) para las actividades agrícolas tradicionales.

Figura 19. A) Azud de Ojós; B) Azud El Menjú

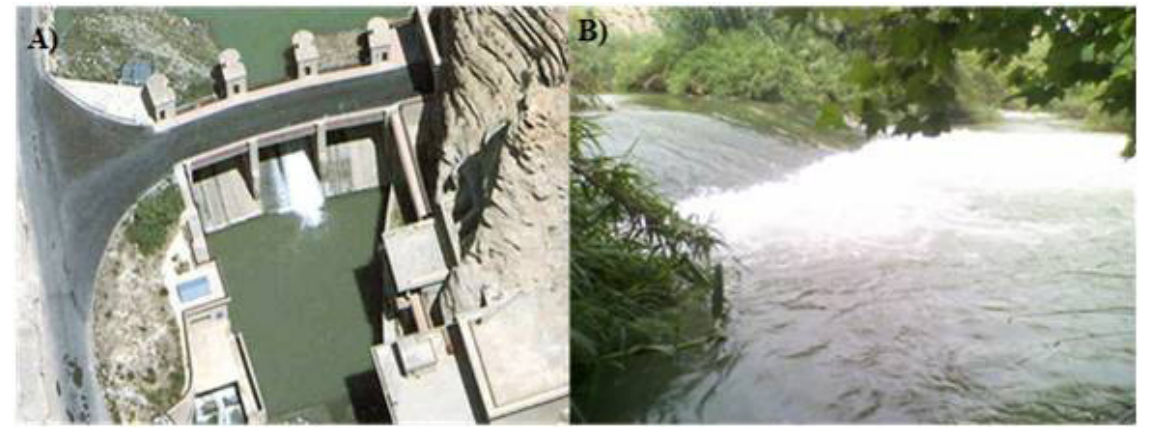

Fuente: A) Confederación Hidrográfica del Segura. B) Panoramio (2018).

Una de las pruebas del uso doméstico, pretérito del agua con carácter colectivo, son los lavaderos, espacios sociales de reunión, que lo fueron, de las mujeres de los pueblos del Valle, al tiempo que lugar donde lavar la ropa u otros enseres (figura 20A, 20B). 
Figura 20. A) Lavadero público de Ojós; B) Lavadero público de Blanca.

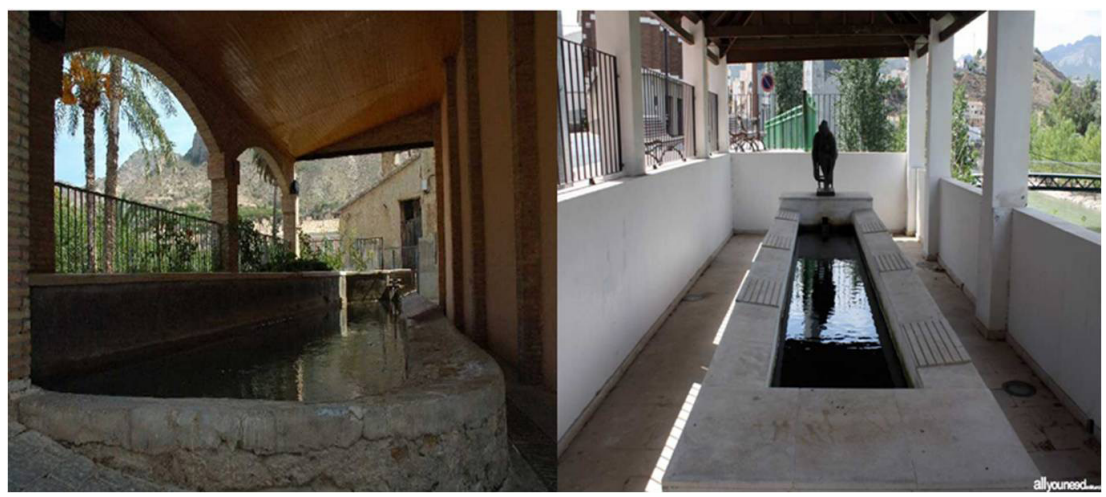

Fuente: A) Juan Crespo.Paperblog; B) http://www.allyouneedinmurcia.com/ (2017).

\subsubsection{Balneario de Archena}

Otros usos del agua en el Valle son medicinales, las aguas termales que emanan en el paraje conocido como Balneario de Archena, ya fueron utilizadas por los íberos en el siglo $\mathrm{V}$ a.C, tiempo después los romanos construirían unas termas para el baño, tal y como lo atestiguan los restos arqueológicos sitos en el mismo balneario (CEPOAT-UM, 2018). En ellos se unen historia y modernidad, así como un entorno natural de gran atractivo constituido por retazos de bosque de ribera asentado entre el balneario y el río Segura (figura 21A, 21B, 21C). En la actualidad constituye un destacado complejo turístico asociado al turismo de salud.

Figura 21. A) Manantial; B) Piscina termal; C) Baño termal.

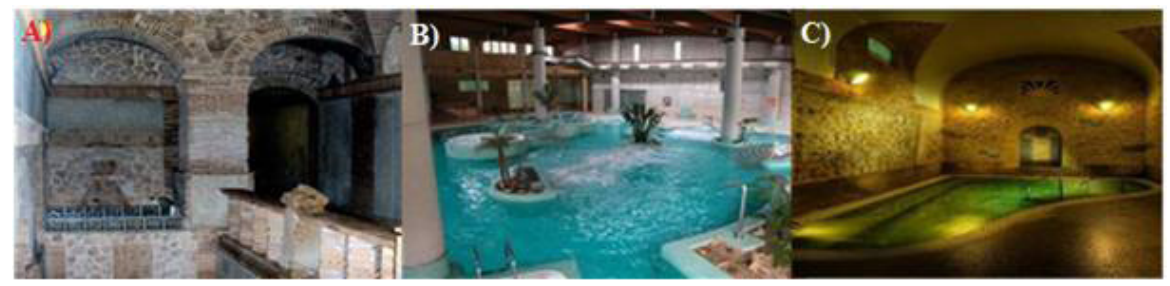

Fuente: A) Región de Murcia Digital; B) viajeselcorteingles; C) TriAdvisor (2018). 
La conjunción territorio, paisaje, patrimonio y herencia cultural como producto turístico: el caso del valle de Ricote (región de Murcia) sureste de España Gest. tur, $\mathrm{N}^{\circ} 29$, enero - junio 2018, pp 31-63.
Miguel Sánchez

Francisco Belmonte

Gustavo Ballesteros

\subsubsection{Las Salinas}

En el Valle se localizan unas infraestructuras en desuso, desconocidas para el público en general, cuyos restos muestran la existencia en el pasado de una actividad económica como es la producción de sal. Su inclusión en este trabajo queda justificada por el uso del agua y por haber dejado un legado histórico, etnográfico, cultural, etc. de considerable interés. Toda esta herencia forma parte del rico patrimonio con que cuenta el Valle. (Núñez y Sánchez-Sánchez, 2016:66). La terna de salinas: Del Curro, El Arco y Salero de Ulea, se inscriben en la modalidad de salinas interiores (figura 22A, 22B, 22C).

Figura 22. A) Salinas del Curro (Ricote); B) Salinas del S. Antonio o El Arco (Ojós); C) Salero de Ulea

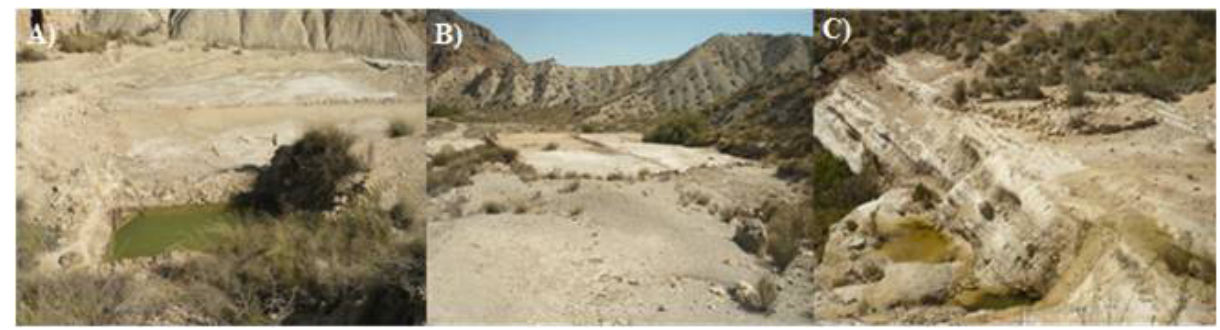

Fuente: Sánchez-Sánchez, M.A. (2015).

En el cuadro 3 se muestra un listado de aquellos elementos declarados Bienes de Interés Cultura [BIC], figura de máxima protección patrimonial otorgada por la Administración Regional.

Cuadro 3. Listado de BIC del área de trabajo.

\begin{tabular}{|c|c|}
\hline MUNICIPIO & DENOMINACIÓN \\
\hline Abarán & Puente Viejo \\
\hline Abarán/Blanca & Yacimiento Cabezo de la Cobertera \\
\hline Archena & Yacimiento Cabezo del Tío Pío, Poblado Ibérico y Necrópolis \\
\hline Blanca & Cacillo de Blanca \\
\hline Cieza & Yacimiento Medina Siyasa \\
\hline Cieza & Castillo de la Atalaya \\
\hline Cieza & Iglesia de San Agustín \\
\hline Ojós & Castillo "Pila de la Reina Mora" \\
\hline Ulea/Ojós & Iglesia de San Sebastián \\
\hline Ricote & Palacete de Los LLamas \\
\hline Ricote & Castillo de Peñascales \\
\hline Ricote & Iglesia de San Bartolomé \\
\hline Ulea & Torre del Puerto de La Losilla \\
\hline Ulea &
\end{tabular}

Fuente: www.patrimur.es (2018). 
Existen otros elementos que tienen incoados expedientes para su declaración futura como BIC, como la iglesia de Villanueva del río Segura, y las norias de Abarán y paraje de El Menjú. A estos hay que adicionar todos aquellos declarados en los distintos Planes Generales Municipales de Ordenación [PGMO] y las Normas Subsidiarias [NNSS]: Casa del Menjú (CIEZA-PGMO, 2008), Iglesia de Blanca (BLANCA-PGMO, 2008), Lavadero público de Ojós (OJÓS-PGMO, 2014), etc.

\subsection{Paisajes culturales}

El artículo $1^{\circ}$ de la Convención del Patrimonio Mundial (UNESCO, 1972) introduce la definición de paisaje cultural, calificando estos como bienes que representan las "obras conjuntas del hombre y la naturaleza", consecuentemente los paisajes del Valle podrían ser considerados como paisajes culturales. Tal proposición se reafirma al profundizar en lo recogido en el citado artículo, donde se dice al respecto que estos paisajes ilustran la evolución de la sociedad humana y sus asentamientos a lo largo del tiempo, condicionados por las limitaciones y/u oportunidades físicas que presenta su entorno natural y por las sucesivas fuerzas sociales, económicas y culturales, tanto externas como internas. Cuestión, ésta, a la que se suma Mateu (2014:256) añadiendo la connotación identitaria basada en la singularidad.

Esta situación se ve reforzada por diversas aportaciones como las realizadas por: Hermosilla e Iranzo (2014) los cuales entienden que el regadío mediterráneo es consecuencia de una adaptación al medio natural y, a su vez, de una dinámica particular que ha dado lugar a un predominio del minifundismo, a una estructura atomizada, claro ejemplo son las huertas tradicionales del Valle. También Mata y Fernández (2010) hacen referencia a esa connotación cultural del paisaje, aunque adjetivándolo quizás con reseñas al agua, al apreciar los paisajes de regadío, incluidos los asentamientos tradicionales asociados, en las regiones de clima mediterráneo como las expresiones más acabadas de los paisajes culturales del agua. Siendo, para dichos autores, culturales y patrimoniales, al expresar una larga historia de modelado de la naturaleza. Además el Valle queda incluido en el "Plan Nacional de Paisaje Cultural" de Ministerio de Educación, Cultura y Deporte de España, constituyendo uno de los 100 paisajes culturales de España (VV.AA, 2016) (figura 23). 
Figura 23. Paisaje Cultural del Valle de Ricote

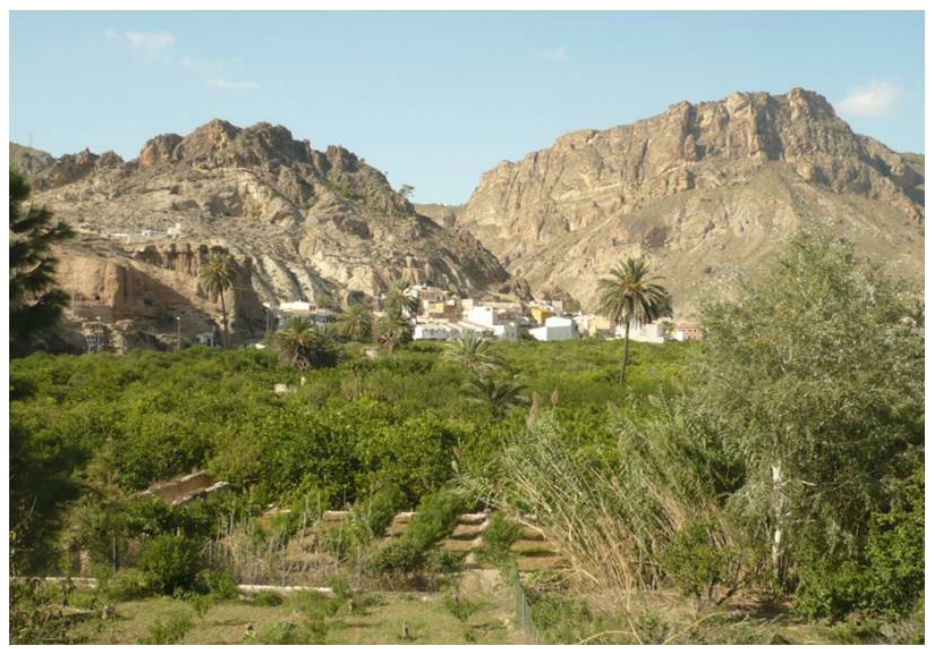

Fuente: Sánchez-Sánchez, M.A. (2015).

Tomando como premisa la definición de atractivo turístico, en la cual se considera existe ese atractivo cuando los recursos cuenta con las condiciones necesarias para ser visitados y disfrutados por el turista (UCI, 2017), se puede afirmar que no todos los recursos turísticos del Valle tienen ese atractivo. No obstante, cabría aceptar que, si tienen un "potencial atractivo turístico" aun por desarrollar, que albergan la posibilidad de motivar al turística o visitante a conocer este territorio, por los valores culturales y naturales de carácter patrimonial expuestos hasta aquí. Puesto que el atractivo está basado, también, en la planta turística, servicios complementarios, medios de transporte, servicios de transporte e infraestructuras básicas, en los siguientes apartados se avanza información, análisis y valoración en torno a estas cuestiones.

\subsection{Planta turística}

Esta es entendida como el conjunto de instalaciones, equipos, empresas y personas que prestan servicio al turismo y fueron creados para este fin (UCI, 2017). Entre los alojamientos del Valle destacan los del Balneario de Archena (figura 24), estos constituyen la mayor oferta hotelera de área de estudio al igual que sucede para el caso de los apartamentos (cuadro 4). 
Figura 24. A) Calle del Balneario; B) Interior de un hotel; C) Hotel.

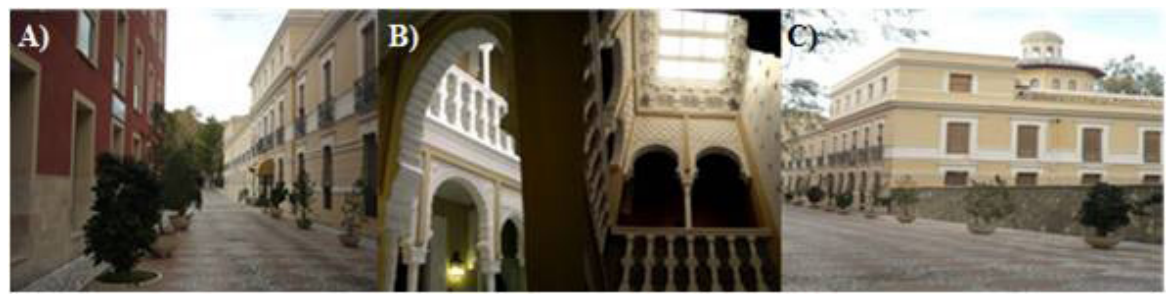

Fuente: A) y C) Sánchez-Sánchez, M.A. (2015); B) Región de Murcia Digital (2018).

Los datos relativos a los alojamientos rurales incluyen los referidos a hospederías como casas rurales. El mayor número de ellos lo encontramos en Villanueva, pero no así la mayor oferta de plazas que corresponde a Cieza. Los alojamientos rurales muestran una mayor distribución territorial frente a la atomización de apartamentos y hoteles, dentro de estos últimos han sido incluidas las pensiones. Por último, cabe decir que el área de estudio cuenta con casi un millar de plazas (cuadro 4).

Cuadro 4. Oferta de hoteles y plazas (2016)

\begin{tabular}{|l|c|c|c|c|c|c|}
\hline \multicolumn{6}{|c|}{ OFERTA DE PLAZAS HOTELES, APARTAMENTOS Y CASAS RURALES } \\
\hline \multirow{2}{*}{} & \multicolumn{2}{|c|}{ HOTEL } & \multicolumn{2}{c|}{ APARTAMENTOS } & \multicolumn{2}{c|}{ ALOIAMIENTO RURAL } \\
\hline & UNIDADES & PLAZAS & UNIDADES & PLAZAS & UNIDADES & PLAZAS \\
\hline Abarán & 1 & 55 & 0 & 0 & 0 & 0 \\
\hline Archena & 6 & 575 & 47 & 118 & 1 & 20 \\
\hline Blanca & 2 & 43 & 0 & 0 & 1 & 24 \\
\hline Cieza & 0 & 0 & 0 & 0 & 2 & 51 \\
\hline Ojós & 0 & 0 & 0 & 0 & 0 & 0 \\
\hline Ricote & 0 & 0 & 0 & 0 & 3 & 24 \\
\hline Ulea & 0 & 0 & 0 & 0 & 1 & 9 \\
\hline Villanueva & 0 & 0 & 23 & 66 & 5 & 48 \\
\hline
\end{tabular}

Fuente: Centro Regional de Estadística de Murcia [CREM] y toprural.com (2017).

Los restaurantes son el otro gran grupo que define la planta turística de un territorio. Elárea de estudio cuenta con 68 establecimientos de este tipo, su número de plazas se sitúa próximo a las 7000. Existen municipios (Villanueva) que no cuentan con ningún restaurante (cuadro 5). 
Cuadro 5. Oferta de restaurantes y plazas (2016)

\begin{tabular}{|c|c|c|}
\hline \multicolumn{3}{|c|}{ OFERTA DE RESTAURANTES Y PLAZAS } \\
\hline & UNIDADES & PLAZAS \\
\hline Abarán & 10 & 1243 \\
\hline Archena & 23 & 1988 \\
\hline Blanca & 7 & 1007 \\
\hline Cieza & 22 & 1088 \\
\hline Ojós & 2 & 1150 \\
\hline Ricote & 2 & 181 \\
\hline Ulea & 2 & 324 \\
\hline Villanueva & 0 & 0 \\
\hline
\end{tabular}

Fuente: Centro Regional de Estadística de Murcia [CREM] (2017).

\subsection{Servicios complementarios}

La distribución de los servicios financieros es tal y como sigue: Abarán (8), Archena (13), Blanca (4), Cieza (13), Ojós (0), Ricote (2), Ulea (1) y Villanueva (1), datos referidos a 2016 (CREM, 2017). Se aprecia un gradiente en cuanto al número de oficinas bancarias, relacionado directamente con el número de habitantes, a mayor número de estos, mayor número de oficinas. Sobresale Ojós por la inexistencia de sucursal bancaria alguna. En lo que respecta a los servicios de salud todas las localidades cuenta con este servicio, aunque no con servicios de urgencias, que por la organización administrativa del Servicio Murciano de Salud [SMS] se centralizan en: Cieza con una Unidad Medicalizada [UME] y un Servicio de Urgencias de Atención Primaria [SUAP], Abarán (1 SUAP) y Archena (1 SUAP). Cuenta el área de estudio con un Hospital en Cieza, en la puerta norte del Valle (murciasalud.es, 2017).

Todos los municipios cuentan con dotación policial (policía local o municipal), además existen cuarteles de la Guardia Civil en Abarán, Archena, Blanca y Cieza. En cuanto a los comercios, estos se distribuyen en relación al tamaño de las localidades, siendo casi inexistentes en Ojós, Ulea, Ricote y Villanueva. 


\subsection{Infraestructuras básicas y medios de transporte}

La existencia de ciertas infraestructuras, consideradas como básicas permiten la accesibilidad al recurso turístico, las vías de comunicación terrestre son las únicas que dan acceso directo al área de estudio. Existe una línea férrea (Madrid-Cartagena) que bordea la zona central del Valle pasando al Este del mismo. Entre las carreteras destacan dos vías de gran capacidad: autovía de Murcia (A-30) (Albacete-Cartagena) y autovía del Altiplano (A-33) (Puerto de la Losilla -Blanca-Fuente La Higuera -Valencia-) esta última culminada sólo hasta Yecla (Murcia). Desde las mismas se puede acceder con bastante prontitud a los pueblos del Valle. Existe en el área de estudio un importante entramado de carreteras de segundo orden de entre ellas destacan las que discurren paralelas al río por el interior del Valle: MU-512 (Cieza-Abarán), MU-514 (Abarán-Blanca), MU-520 (Blanca-Villanueva), y MU-522 (Archena-Villanueva). A estas se suman las de tercer orden que unen el Valle central con su periferia: Abarán- $B^{\circ}$ San José, Blanca-San Roque, Ulea-A30, Ojós-Ricote, Villanueva-B ${ }^{\circ}$ Providencia, etc.

Mediante el uso de las vías de comunicación citadas, se puede acceder con vehículos privados o bien servicios públicos discrecionales. Pero existen otros medios de transporte hasta el Valle de Ricote, como son los denominados públicos (autobús y tren). El primero cuenta con dos líneas permanentes: Línea 42 Blanca-Murcia por Blanca, Ojos, Ricote, Villanueva, Ulea y Archena, Villanueva- hacia Murcia (LATBUS, 2018) y línea Murcia-Cieza por Abarán y Molina de Segura (LYCAR-Grupo Interbus, 2018). El otro medio es la línea ferroviaria Murcia-Madrid, con parada en las estaciones de Archena-Molina de Segura y Cieza.

\subsection{Zona de influencia}

Resulta de interés conocer el área de influencia que puede llegar a tener el Valle de Ricote desde una perspectiva turística, para ello el criterio seguido será la proximidad geográfica de los potenciales visitantes y/o turistas. La distancia media desde el Valle a algunas ciudades es: Murcia (27 km.), Cartagena (78 km.), Lorca (78 km.), Caravaca de la Cruz (61 km.), Yecla (80 km.), en la Región de Murcia; Orihuela (47 km.), Elche $(71 \mathrm{~km}$.), Alicante $(89 \mathrm{~km}$.) y Villena $(90 \mathrm{~km}$.), en la provincia de Alicante; Hellín (50 km.) en la provincia de Albacete. La Región de Murcia cuenta con una población de 1.466.818 habitantes, tanto éstos como los de la provincia de Alicante, de modo aproximado, sobre todo los residentes de las comarcas de la Vega Baja del Segura (200.000), Bajo Vinalopó (300.000), Medio Vinalopó (172.000), Campo de Alicante (455.00) y Alto Vinalopó (54.000), y en la provincia de Albacete: Campos de Hellín (45.000) (INE 2017), suponen un volumen de potenciales turistas de 2.692.818. 


\section{CONCLUSIONES}

El territorio del Valle de Ricote alberga un destacado patrimonio cultural con considerable valor, todo ello resultado de esa relación entre naturaleza y sociedad, que ha dejado una herencia marcadamente cultural, patente en los diversos paisajes existentes. Estos actúan como síntesis de una simbiosis entre la sociedad que se ha adaptado y/o a utilizado los recursos y/o dificultades que la naturaleza a puesto a disposición de los distintos grupos humanos que han habitado el Valle, desde la prehistoria, pasando por romanos, árabes, etc. hasta nuestros días. Estos paisajes se erigen en reflejo de diversos hitos geográficos, materiales e inmateriales, los cuales en ocasiones podrían ser calificados de paisajes naturales, paisajes del agua, paisajes hidráulicos en síntesis culturales, siendo reflejo de la conjunción de territorio, patrimonio y herencia cultural.

El Valle cuenta con diversidad de elementos que pueden ser considerados como recursos turísticos destacando: el Balneario de Archena, los restos arqueológicos de la ciudad de Medina Siyâsa y Bolvax (Cieza), las iglesias del Valle, los artilugios hidráulicos (azudes, acequias, norias, etc.), castillos, sede de la Encomienda del Valle de Ricote (Ricote), espacios naturales (río Segura, Sierra de La Pila, Sierra de Ricote, La Navela y Yesos de Ulea, etc.), etc. A estos hay que añadir los de carácter inmaterial (la veneración a la Santísima y Vera Cruz en Ulea, por la presencia del Liniun Crucis, y los encierros de Blanca). Todos ellos, junto a otros tantos, dan lugar a la huella cultural sobre el territorio, reflejándose en sus paisajes, pudiéndose afirmar que los paisajes del Valle también son un recurso turístico de interés.

Los potenciales turistas pueden ascender a casi 2.700 .000 personas. La oferta hotelera de mayor entidad se sitúa en el Balneario de Archena. En cuanto a la accesibilidad al área de estudio en general es bastante aceptable, por la existencia de las autovías y carreteras comarcales interiores. No obstante, sería deseable seguir avanzando en cuestiones de accesibilidad y en una mayor oferta hotelera, ya que en localidades como Ojós, Ricote y Ulea es exigua o inexistente. Finalmente se puede afirmar que el Valle de Ricote constituye un producto turístico, a desarrollar, cuyo interés se sitúa en la potencialidad de sus recursos turísticos, destacando sus paisajes como síntesis territorial que recoge la singularidad de esta área. 


\section{BIBLIOGRAFÍA}

AYTO. ARCHENA (2018). Ayuntamiento [AYTO.] de Archena. En: www.archena.es, consultado el 18/01/2018.

AYTO. RICOTE (2018). Ayuntamiento [AYTO.] de Ricote. En: www.ricote.es, consultado el 09/01/2018.

BLANCA-PGMO (2008). Ayuntamiento de Blanca-Plan General Municipal de Ordenación [PGMO].

BORM (2014). Orden del Excmo. Sr. Consejero de Obras Públicas y Ordenación del Territorio, de fecha de 23 de diciembre de 2013, relativa a la aprobación inicial de las directrices y Plan de Ordenación Territorial del Río Mula, Vega Alta y Área Oriental de la Región de Murcia. Boletín Oficial de la Región de Murcia [BORM], Número 25 de 31 de enero de 2014.

Calvo García-Tornel, F. y López Bermúdez, F. (2014). "Valle de Ricote, escenario en donde se funden las historias geológica, geomorfológica y humana". MVRGETANA, ${ }^{\circ}$ 131, Año LXV, Pági. 35-47.

Canalís Hernández, O. (2014). "El interés por el paisaje. Visión naturalista, cultural y sintética". En Fundicot, VII Congreso Internacional de Ordenación del Territorio (VII CIOT), Madrid, Fundicot, pp. 680-691.

Carrillo Espinosa, J. (2014) "Artesonado Mudéjar en la monumental iglesia de Ulea". En: http://www.cronistasoficiales.com/?p=15994, consultado el 09/01/2018.

Castillo Ruíz, J. y Martínez Yáñez, C. (2014). "El Patrimonio Agrario: Definición, caracterización y representatividad en el ámbito de la UNESCO". Boletín de la Asociación de Geógrafos Españoles nº 66, pp. 105-124.

CEPOAT-UM (2018). Balneario romano de Archena-Murcia. Centro de Estudios del Próximo Oriente y la Antigüedad Tardía [CEPOAT]. Universidad de Murcia [UM]. En: http://www.um.es/cepoat/archena/?page_id=151, consultado el 10/01/2018.

CIEZA-PGMO (2008). Ayuntamiento de Cieza-Plan General Municipal de Ordenación [PGMO].

CONSEJO DE EUROPA (2000). Convenio Europeo del Paisaje.

CREM (2015). "Población a según edad, sexo y municipios" Centro Regional de Estadística de Murcia [CREM]. En: http://econet.carm.es/web/crem/inicio/-/crem/sicrem/ PU_padron/p15/sec2_sec2_14.html, consultado el 30/12/2017

Donaire, J.A. y Gordi Serrat J. (2003). "Bosque y turismo". Boletín de la Asociación de Geógrafos Españoles, nº 35, pp. 207-221.

Estrategia Forestal de la Región de Murcia (2003). "Estrategia Forestal de la Región de Murcia (Documento de debate)". Consejería de Agricultura, Agua y Medio Ambiente, Dirección General de Medio Natural.

Gómez, J. (2016). “Medina Siyasa: la legendaria joya de Cieza”. En: http://cronicasdesiyasa.es/medina-siyasa-legendaria-joya-cieza/, consultado el 08/01/2018. 
Hermosilla Pla, J. eIranzo García, E. (2014). “Claves geográficas para la interpretación del patrimonio hidráulico mediterráneo. A propósito de los regadíos históricos valencianos". Boletín de la Asociación de Geógrafos Españoles nº66, pp. 49-66.

LATBUS (2018). "Líneas de autobuses". En: http://www.latbus.com/, consultado el $12 / 01 / 2018$

LYCAR-GRUPO INTERBUS (2018). Ruta Cieza-Murcia. En: www.lycar.es, consultado el 12/01/2018.

Mata Olmo, R. y Fernández Muñoz, S. (2010). "Paisajes y patrimonios culturales del agua. La salvaguarda del valor patrimonial de los regadíos tradicionales" en Scripta Nova. Revista electrónica de Geografía y Ciencias Sociales, Vol. XIV, nº 337. Universitat de Barcelona. En: http://www.ub.edu/geocrit/sn/sn-337.htm, consultado el 08/01/2018

Mateu i Lladó, J. (2014). "Los paisajes culturales patrimonio de la mundial como herramientas de gestión territorial. El caso de la serra de Tramuntana de Mallorca". Boletín de la Asociación de Geógrafos Españoles nº 66, pp. 253-270.

Núñez, M.A.; Sánchez-Sánchez, M.A. (2016). "Salinas del Valle de Ricote: paisaje y patrimonio". En: Francisco Belmonte Serrato, et al. (Coord.) Cuestiones sobre Paisaje, patrimonio natural y Medio Ambiente en el Sureste Ibérico. Editum, Universidad de Murcia, pp. 65-72.

OJÓS-PGOM (2014). Ayuntamiento de Ojós-Plan General Municipal de Ordenación [PGMO].

OMT [Organización Mundial del Turismo] (2017). "Entender el turismo: glosario básico”. En: http://media.unwto.org/es/content/entender-el-turismo-glosario-basico, consultado el 22/12/2017

Palazón Cuadrado, J.

2011. Documentos de la Encomienda de Ricote 1285-1850. Orden de Santiago. Edita: Jesús Palazón Cuadrado. Murcia.

Pelegrín Garrido, M.C. (2012). "Obras hidráulicas históricas en el Valle de Ricote" en Actas de las II Jornadas de Investigación y Divulgación sobre Abarán y el Valle de Ricote, pp. 191-204

Región de Murcia Digital (2015). "Ulea”. En: http://www.regmurcia.com/, consultado el 09/01/2018.

Silva Pérez, R. (2008). "Hacia una valoración patrimonial de la agricultura". En Scripta Nova Revista Electrónica de Geografía y Ciencias Sociales, vol.XII, nº 275.

Silva Pérez, R. (2014). "Caracterización de paisajes en pequeñas y medianas ciudades. Propuesta metodológica aplicada a Constantina (Sierra Norte de Sevilla)". Boletín de la Asociación de Geógrafos Españoles, nº 64, pp. 297-319. 
Sánchez-Sánchez, M.A., Belmonte Serrato, F., y García Marín, R. (2014). “Los paisajes culturales del Valle de Ricote (Región de Murcia) como espacios patrimoniales y recursos/productos turísticos". En FUNDICOT, Madrid, FUNDICOT, VII Congreso Internacional de Ordenación del Territorio.

Sánchez-Sánchez, M.A.; García Marín, R.; Belmonte Serrato, F. (2015). "El Valle de Ricote en la Región de Murcia como recurso patrimonial e identidad cultural". En Análisis espacial y representación geográfica: innovación y aplicación, de la Riva, J. et al. (Eds.). Zaragoza: Universidad de Zaragoza-AGE, 1211-1219.

Sánchez-Sánchez, M.A.; Belmonte Serrato; F.; García Marín, R. (2016). “Los paisajes del agua del Valle de Ricote en la Región de Murcia”. En: Francisco Belmonte Serrato, et al. (Coord.) Cuestiones sobre Paisaje, patrimonio natural y Medio Ambiente en el Sureste Ibérico. Editum, Universidad de Murcia, pp. 133-139.

Sánchez-Sánchez, M.A. (2017) "Marco teórico-referencial para la protección, gestión y ordenación del paisaje. El caso de la Región de Murcia”. Espacio, tiempo y forma, Serie VI.Geografía, 10.2017, pp. 257-280.

TURISMO (2007) "Plan Turístico Español Horizonte 2020”. En: http: //www.tourspain. es, consultado el 22/12/2017

UCI [Universidad para la Cooperación Internacional] (2017). "Conceptos fundamentales de turismo". En: http: //www.ucipfg.com/Repositorio/MGTS/MGTS15/ MGTSV15-07/semana3/LS3.2.pdf, consultado el 22/12/2017 UNESCO (1972). "Textos básicos de la Convención de Patrimonio Mundial de 1972". En http://whc.unesco.org/uploads/activities/documents/activity-562-2.pdf, consultado el 27/12/2017.

Vicedo Pellín, M. (2011). "El Espacio Urbano”. En https:/es.slideshare.net/mariomasero/t9-1-2-concepto-de-ciudad-y-2-proceso-de-urbanizacin, consultado el 30/12/2017 VV.AA. (2016). 100 paisajes culturales en España. Ministerio de Educación, Cultura y Deporte, Madrid. 